part-time medical officers of health, have now so far modified their position as to suggest that the Local Government Board " may" insist upon the same terms of appointment for part-time medical officers of health (in cases where the Board shall deem it desirable) as are proposed for whole-time officers.

Our Council has unanimously resolved that to distinguish, in respect of tenure, between part-time and whole-time medical officers of health is, in the public interest, undesirable; and has decided to oppose in Parliament any Bill which seeks to introduce such distinction.

(v.) Mr. F. E. Fremantle, F.R.C.P., F.R C.S., county medical officer of health for Hertfordshire, proposes to read, before the Section of State Medicine, at the meeting of the British Medical Association in July, a paper on "The Work of the Part-time Medical Officer of Health," and to move :-

" That part-time medical officers of health have in the past played a most important part in the advancement of public health; that their special clinical experience, their personal intimacy with patients, and their comparative financial independence give them exceptional opportunities for securing acceptance of their views ; and that the interests of public health will be best promoted by securing a better education of all medical men in public bealth work than in making any rule to separate preventive from curative work in the activities of the medical profession."

It is particularly hoped that plenary support will be given to Mr. Fremantle, both by attendance and in debate.

(vi.) It has been arranged to hold a general meeting of our Association, in connexion with that of the British Medical Association, on July 29th. The exact time and place will be announced later, but a full attendance is looked for, as an opportunity will arise for discussing the decision which will, by then, have been arrived at by the Representative Meeting in respect of Minute 234 and the consequent notices of motion.

(vii.) A dinner will be held at the Holborn Restaurant on Friday, July $29 t h$, at 7.30 P.M. Tickets, 5s. $6 d$. each, exclusive of wine. The presence of official guests of influence and distinction is expected, and the Council will be much assisted if gentlemen who propose to attend (with or without bringing personal guests) will kindly notify their intention by card as early as possible in June to the hon. secretary, Dr. Belilios, Queen's-road, Wimbledon, S.W. We are, Sir, yours faithfully,

F. G. Crookshank, Chairman.

D. A. Belilios, Hon. Secretary.

F. G. GIBbs-Smith, Hon. Treasurer. Health.

London, S.W., June 1st, 1910.

\section{THE OPERATION FOR CLEFT PALATE.} To the Editor of THE LANCET.

SrR,-The letters of Mr. T. H. Kellock and Mr. R. W. Murray in the recent issues of THE LANCET on this subject are of great interest. I quite agree with Mr. Murray that it would be very instructive if those surgeons who advocate the early flap operation would bring forward their patients and show us the results of the operation. But I am afraid we shall have to wait, for a short time ago, with a view to investigating the after results of the early flap operation and to compare them with those of operations performed at a later period of life, $I$ requested permission to examine the records of one of the children's hospitals in London, where understand this operation is frequently performed. It would almost appear as if the results were not so brilliant as we have been led to believe. Otherwise it is difficult to understand the reticence of the advocates of the early flap operation to bring forward their cases or to allow an impartial, and, I hope, a scientific, investigation to take place. It is possible, however, that we may have a full report from this hospital, as I was told "it seems likely that some of the staff will utilise the same material."

At the Leicester meeting of the British Medical Association in $1905 \mathrm{Mr}$. James Berry read a paper on 67 consecutive cases he had operated on by the older method at ages varying from 2 years to 16 years, and he showed a number of his patients, thereby allowing everyone to judge for himself what his results were. Surely it ought not to be impossible in London to get together a number of cases of the early flap operation and enable everyone to see how badly or how well the patient speaks. A comparison of the two sets of cases would also be possible. In the early part of this year I saw two children of 10 years who had been operated on in London at three years of age by the flap method, and certainly the results, neither as regards speech nor the closure of the cleft, encouraged me to depart from the older method of operating. Possibly these are two more exceptionally bad examples. The mere closure of the cleft is not the most important thing : to give the patient a freely moveable well-formed soft palate is what should be always aimed at, and how is a flap composed of mucous membrane only to do this? I am, Sir, yours faithtully,

Harley-street, W., June 6th, 1910.

T. P. LEGG.

\section{IS APPENDICITIS CONTAGIOUS?}

To the Editor of THE LANCET.

SIR,-In the Times of a few days ago appeared a short paragraph stating that the medical officer of bealth for the Farnham rural district had reported to the council that appendicitis had increased in bis district to an alarming extent. The increase of the disease is only too well known, and most practitioners of medicine must be fully alive to the fact, but, so far as $I$ know, the statement alluded to above is the first indication that the disease may so decidedly affect a limited district or locality. We all recognise the fact that there is, and has been for some ten years, a very marked increase in the prevalence of the disease, but I question whether it is as generally recognised that the type of the disease has altered and that the specific virulence bas also altered and increased.

In a clinical lecture on appendicitis given by me at the West London Hospital in February, 1897, I spoke of those attacks of sudden acute onset usually associated with an appendix rapidly becoming gangrenous, and I remarked that, based on an experience of some 20 years of active hospital work, such cases were happily comparatively rare, and that but few had come under my personal care. An old house physician of about that period stated that during his six months of office, as far as he could remember, no case of the character had been under his care. Gradually a change of type supervened, and within a few years of the date of making the statement $I$ have just quoted, instead of seeing case after case of appendicitis running a simple benign course and speedily recovering under medical treatment, we have been called upon to deal with a vast number in which a rapidly sloughing or gangrenons appendix necessitated immediate operation, and it would not be an exaggeration to say that whereas in the "seventies" and "eighties" those cases were only met with comparatively rarely, they are now of almost daily occurrence.

Many reasons have been assigned from time to time as causes for the remarkable increase of the disease. It is not my intention to discuss them; one and all they appear to me to be insufficient to explain as a common cause an illness appearing under such a multitude of varying conditions. But if we recognise that with a marked increase of the disease there has also been a change of type as regards its virulence, and that within the memory of many now living a disease which formerly ran a fairly constant benign course under a simple medical treatment has become not only far more frequent but has also assumed a much more serious form, it seems to me to afford a hypothesis which may give a clue to the true underlying cause of the disease, and justifies the assumption that in appendicitis we are dealing with the local effect of a pernicious organism, possibly but a virulent variety of the bacillus coli communis, the organism affecting a locality or nidus which by its anatomical position produces, when affected by a destructive lesion, such disastrous consequences.

Have we not in the behaviour of another pernicious organism, that of diphtheria, a somewhat analogous course? Fifty years ago it was a comparatively rare disease, and if we take the clinical description as given by the late Sir William Jenner in his classical lecture delivered in 1861, not only presenting different clinical aspects, but of a vastly 